GRASAS Y ACEITES, 62 (1), ENERO-MARZO, 21-28, 2011, ISSN: 0017-3495

DOI: $10.3989 /$ gya.045210

\title{
Vegetable oil basestocks for lubricants
}

\author{
By Rafael Garcés Enrique Martínez-Force and Joaquín J. Salas
}

Instituto de la Grasa (CSIC), Av. Padre García Tejero, 4, 41012, Sevilla.

( ${ }^{\star}$ Corresponding author: rgarces@ cica.es)

\section{RESUMEN}

\section{Bases de aceite vegetal para lubricantes}

El uso de bases vegetales biodegradables para aceites lubricantes presenta varias ventajas sobre las mucho más extendidas bases minerales. Estas ventajas se centran sobre todo en su biodegradabilidad, en ser un recurso renovable de producción local, en su lubricidad y en su índice de viscosidad, presentando además costes más bajos que las bases sintéticas. Sin embargo, estas ventajas no han extendido el uso de bases vegetales ni en industria ni en automoción debido a su menor estabilidad y sus mayores puntos críticos de fluidez. Los aceites vegetales son ésteres de ácidos grasos y glicerol y sus propiedades físico-químicas dependen principalmente de su composición acílica. Así, para asegurar los máximos niveles de estabilidad manteniendo un comportamiento aceptable a bajas temperaturas los ácidos grasos monoinsaturados son los más apropiados para este fin. Además, la presencia de antioxidantes naturales también mejora las propiedades como lubricantes de estas bases vegetales. Estos aceites requieren por lo demás aditivación para mejorar su valor de viscosidad, estabilidad oxidativa y propiedades a bajas temperaturas. En el presente trabajo se realizó una revisión de las fuentes de aceites vegetales adecuadas para la elaboración de biolubricantes, así como de sus propiedades y posibles mejoras, su producción, usos y aditivación.

PALABRAS-CLAVE: Ácido graso monoinsaturado - Aditivos de lubricantes - Base vegetal - Biodegradable - Lubricante.

\section{SUMMARY}

\section{Vegetable oil basestocks for lubricants}

The use of vegetable biodegradable basestocks for lubricant oils present several advantages over the much more extended mineral bases. These advantages refer to biodegradability, a renewable feedstock of local production, lubricant and viscosity index and lower costs than synthetic lubricant bases. Despite these benefits, their use in industry and motor vehicles is not yet extensive due their lower stability and higher pour points. Vegetable oils are esters of fatty acids and glycerol, and their physicochemical properties rely mainly on the composition of their acyl moieties. Thus, to assure the maximum levels of stability while maintaining acceptable behavior at low temperatures, monounsaturated fatty acids are preferred for this purpose. The presence of natural antioxidants also improves the properties of these vegetable based stocks as lubricants. These oils usually require additives to improve their viscosity value, oxidative stability and properties at low temperatures. In the present work, the different sources of vegetable oils appropriate for biolubricant production were reviewed. Their properties and the future improvement of the oil bases, oil based stock production, uses and additives are discussed.

KEY-WORDS: Biodegradable - Lubricant additives - Lubricant - Monounsaturaed fatty acids - Vegetable basestocks.

\section{INTRODUCTION}

Lubricant oils have the function of decreasing the friction coefficient between two contacting surfaces. Their use is necessary for the correct function of almost the totality of mechanical machinery working in the world. The requirements for commercial lubricant oil are usually very demanding in terms of stability, viscosity, lubrication and range of working temperatures. Lubricant oils consist of up to $80 \%$ of oily basestocks which confer their properties of viscosity, stability and pour point to the lubricant plus additives supplemented to improve these properties. Most lubricant oils used in the world contain mineral basestocks consisting of hydrocarbons obtained from heavy fractions resulting from crude oil refining (Rudnik, 2005). The composition of these basestocks is complex, containing molecules of different size and structure including branched aliphatic and aromatic hydrocarbons. There are synthetic basestocks that are produced by means of the polymerization of certain pure compounds previously synthesized and purified from fossil carbon sources (Rudnik, 2005). In this case the properties of the oil can be controlled more strictly by acting on the type of monomers and the degree of polymerization. Finally, lubricant oils can be formulated using vegetable oils as the oily base (Erhan and Asadauskas, 2000). Vegetable oils have the advantage over mineral and synthetic basestocks of being a renewable resource that can be locally produced and represent the future alternative to fossil carbon-based substrates. Moreover, they can be used without any additional transformation, which makes them price-competitive against the higher costs of synthetic basestocks. The main advantage of these basestocks is they are fully biodegradable compared with highly contaminant mineral and synthetic basestocks (Battersby, 2000). Nevertheless, the use of vegetable oils for lubricant formulation has the drawback of having lower 
versatility ranges of use than mineral bases. Thus, vegetable oils are triesters of straight-chained mostly unsaturated fatty acids and glycerol that present lower stability and higher pour points than mineral or synthetic oily bases, which can embrace a much higher variety of compounds (Erhan and Asadauskas, 2000). This lack of versatility can be compensated by chemically modifying fatty acids present in the oil by the formation of estolides (Isbell et al. 2006; García-Zapateiro et al. 2010) or modifying double bonds by epoxydation to give place to a versatile intermediate for the synthesis of ether branched chains (Campanella et al., 2010). Another possibility is rearranging the acyl moieties after the hydrolysis of the oil (Cermak and Isbell, 2001). However, these basestocks were not the objective of this review and we only referred to the actual state of the art of the use of unmodified vegetable oils in biolubricant formulation.

\section{VEGETABLE OILS}

Vegetable oils are esters of glycerol with fatty acids (Figure 1) with the exception of the jojoba oil, which consists of esters of fatty acids with long chained alcohols. The chain length of these fatty acids usually ranges from $\mathrm{C} 12$ to $\mathrm{C} 22$. So, fatty acids account for about $85 \%$ of the weight of the vegetable oils determining their properties (Gunstone et al. 2007).

\subsection{Fatty Acids composition determine the properties of vegetable oils}

Oilseeds accumulate a great variety of fatty acids (up to 300) including many with different functional groups (Badami and Patil, 1980). However, the number of fatty acids that can be found in oil crops is much lower. So, they are usually fatty acids of 12 to 22 carbon atoms with different degrees of unsaturation. These fatty acids displayed all double bonds in the cis conformation and separated by one methylene group. The most common fatty acids found in vegetable oil basestocks are shown in Table 1. The chain length and number of double bonds affect the physical properties of fatty acids. Thus, a longer number of carbons involves higher melting points and higher viscosities, whereas the presence of double bonds strongly affect the way in which fatty acids interact when crystallizing, producing substantial decreases in their melting points. A higher number of double bonds also cause a decrease in the fatty acid viscosity and so it will seriously affect the rheological properties of the oil (Table 1). Saturated fatty acids, without any double bond, have very good resistance to oxidation, but tend to be solid at room temperature, whereas polyunsaturated fatty acids are unstable against oxidation but liquid at temperatures below $0^{\circ} \mathrm{C}$ (Table 1). Monounsaturated fatty acids display a good combination of low melting points, stability and viscosity (Noureddini et al., 1992). The evolution of the oxidation of high oleic versus standard sunflower oils shows that a higher content of oleic acid gives a higher termooxidative resistance, with low peroxide value and polymer formation (Marmesat et al., 2009). The relative rates of autoxidation for oleic, linoleic and linolenic acids are well known and they give good notice of their stability. Thus, if we give the value 1 to the oleic acid autooxidation rate, linoleic and linolenic fatty acids will display values of 27 and 77 respectively (Gunstone, 2004), which means they are much more unstable and eas to oxidize. Therefore, oils with high proportions of oleic acid would be much more resistant to oxidation than oils containing similar proportions of linoleic or linolenic acids.

\subsection{Triacylglycerols in vegetable oils}

Chemically, vegetable oils are completely different from mineral oils. They are mixtures of triacylglycerols (TAGs), whose properties depend on the fatty acid they have esterified to their glycerol backbone (Table 2). The TAGs that are found in oil seeds usually display the saturated fatty acids in the sn-1,3 positions, whereas the sn-2 position of glycerol is esterified to an unsaturated or polyunsaturated acyl moiety. This is caused by the specificity of the different enzymes participating in their biosynthesis (Ohlrogge and Browse, 1995). Trisaturated fatty acids are not common in plants growing in temperate climates but they can be found in oils from tropical species (Gunstone et al., 2007), mainly in palm oil and lauric fats (coconut and palm kernel fats). They are not suitable for lubrication due to their high melting points (Table 2), so they should be removed from native oils by techniques of fractionation.

\subsection{Oil crops producing biolubricant bases}

Cultivated vegetable oils are not appropriate for producing biolubricants (Table 3 ) because they

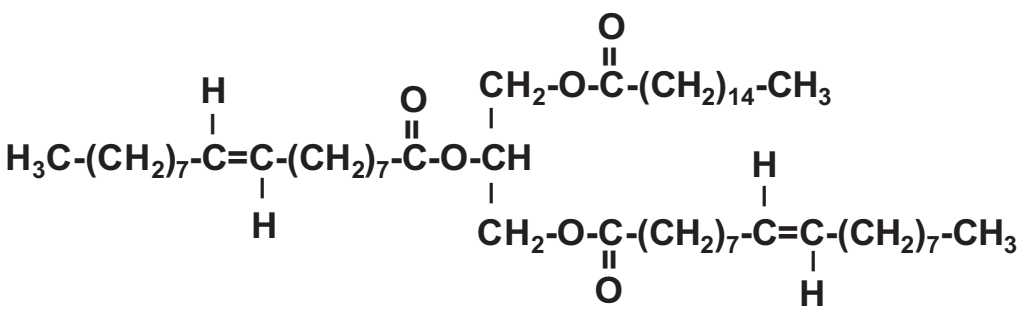

Figure 1

TAG molecule of a standard dioleyl palmitoyl glycerol. 
Table 1

Fatty acids found in standard vegetable oils

\begin{tabular}{|c|c|c|c|c|c|}
\hline Fatty acid type & Systematic Name & $\begin{array}{l}\text { Common } \\
\text { Name }\end{array}$ & Short Name & $\begin{array}{c}\text { Melting } \\
\left.\text { Point ( }{ }^{\circ} \mathbf{C}\right)\end{array}$ & $\begin{array}{c}\text { Viscosity } \\
80^{\circ} \mathrm{C} \\
\text { (cST) }\end{array}$ \\
\hline \multirow[t]{6}{*}{ Saturated } & Dodecanoic & lauric & $12: 0$ & 44.8 & 4.12 \\
\hline & Tetradecanoic & myristic & $14: 0$ & 54.4 & 5.49 \\
\hline & Hexadecanoic & palmitic & $16: 0$ & 62.9 & 7.41 \\
\hline & Octadecanoic & stearic & 18:0 & 70.1 & 8.67 \\
\hline & Eicosanoic & arachidic & $20: 0$ & 76.1 & \\
\hline & Docosanoic & behenic & $22: 0$ & 80.0 & \\
\hline \multirow[t]{2}{*}{ Monounsaturated } & Hexadecenoic & palmitoleic & $16: 1^{\Delta 9}$ & 0.5 & \\
\hline & Octadecenoic & oleic & $18: 1^{\Delta 9}$ & 16.2 & 6.55 \\
\hline \multirow[t]{2}{*}{ Polyunsaturated } & octadecadienoic & linoleic & $18: 2^{\Delta 9,12}$ & -5.0 & \\
\hline & octadecatrienoic & linolenic & $18: 3^{\Delta 9,12,15}$ & -11.0 & \\
\hline
\end{tabular}

content high levels of polyunsaturated fatty acids, which reduce their oxidative stability and/or saturated fatty acids that reduce fluidity at low temperatures. In particular, both soybean and canola oils contain linolenic acid, a fatty acid very susceptible to oxidation. Corn and common sunflower oils contain high proportions of linoleic acid that makes them unstable too. Only in two cases, the content in monounsaturated fatty acids (oleic acid) is higher than $50 \%$ of the total fatty acids, one is canola and the other is palm oil. The last one, due to its high content of saturated palmitic acid, is solid at room temperature.

\subsection{Biotechnology and new oil bases}

Increasing the performance of regular oil crops as biolubricants has been one of the main targets of modern oil crop biotechnology. Thus, the main target of reducing the levels of polyunsaturated fatty acids in regular oil crops has been accomplished by mutagenesis and genetic engineering techniques giving place to a series of oils with high or very high levels of oleic acid that make them much better basestocks for biolubricants (Table 4). High oleic oils are produced by total or partial inhibition of the oleic acid desaturation step, which usually involves the repression of the reticular FAD2 enzyme (Hongtrakul et al., 1998). The first commercial oil crop displaying this phenotype was the high oleic sunflower (Soldatov, 1976) obtained by seed mutagenesis and breeding. Since then, other oil crops with high contents of oleic acid have been developed by techniques of breeding, mutagenesis and genetic engineering (Table 4).

Among the oils in table 4, the high oleic castor seed oil represents a very special case (Rojas-Barros et al., 2004). Standard castor has

Table 2

Properties of some common triglyceride species

\begin{tabular}{cllcc}
\hline \multirow{2}{*}{ TAG type } & \multicolumn{1}{c}{ Name } & Short & $\begin{array}{c}\text { Melting point } \\
\text { (oC) }\end{array}$ & $\begin{array}{c}\text { Viscosity } \\
\mathbf{8 0} \text {-C } \\
\text { cST }\end{array}$ \\
\hline \multirow{2}{*}{ Trisaturated } & Glyceryl tripalmitine & PPP & 66.4 & 13.17 \\
& Glyceryl tristearate & SSS & 73.5 & 16.31 \\
& Glyceryl distearate oleate & SOS & 42.0 & \\
& Glyceryl distearate linoleate & SLS & 37.0 \\
Monosaturated & Glyceryl palmitate oleate stearate & POS & 37.0 \\
& Glyceryl palmitate dioleate & POO & 18.5 \\
& Glyceryl palmitate dioleate & SOO & 23.0 \\
& Glyceryl palmitate dilinoleate & PLL & -3.0 \\
& Glyceryl stearate oleate linoleate & SOL & -4.0 \\
& Glyceryl trioleate & OOO & 5.0 \\
& Glyceryl trilinoleate & LLL & -11.0 \\
& Glyceryl trilinolenate & LnLnLn & -24.2 \\
\hline
\end{tabular}


Table 3

Fatty acid composition of standard vegetable oils

\begin{tabular}{lcccccccc}
\hline & $\mathbf{C 1 6 : 0}$ & $\mathbf{C 1 8 : 0}$ & $\mathbf{C 1 8 : 1}$ & $\mathbf{C 1 8 : 2}$ & $\mathbf{C 1 8 : 3}$ & $\mathbf{C 2 0 : 0}$ & $\mathbf{C 2 0 : 1}$ & $\mathbf{C 2 2 : 0}$ \\
\hline Soybean & 10.9 & 4.2 & 26.5 & 46.1 & 8.2 & 2.1 & 1.4 & 0.2 \\
Corn & 12.0 & 2.3 & 28.5 & 52.0 & 1.9 & 1.9 & 1.3 & 0.0 \\
Sunflower & 6.3 & 4.9 & 35.4 & 51.0 & tr. & 0.3 & tr. & 0.8 \\
Canola & 5.1 & 2.3 & 54.4 & 21.5 & 10.1 & 2.9 & 3.1 & 0.2 \\
Palm & 44.3 & 4.6 & 38.7 & 10.6 & 0.2 & 0.3 & tr. & tr. \\
\hline
\end{tabular}

C16:0 = palmitic acid; C18:0 = stearic acid; C18:1 = oleic acid; C18:2 = linoleic acid; C18:3 = linolenic acid; C20:0 = araquidic acid;

C22:0 = behenic acid; C20:1 = eicosenoic acid.

Table 4

Fatty acid composition of high oleic oilseeds

\begin{tabular}{lccccccccc}
\hline & $\mathbf{C 1 6 : 0}$ & $\mathbf{C 1 8 : 0}$ & $\mathbf{C 1 8 : 1}$ & $\mathbf{C 1 8 : 2}$ & $\mathbf{C 1 8 : 3}$ & $\mathbf{C 2 0 : 0}$ & $\mathbf{C 2 0 : 1}$ & $\mathbf{C 2 2 : 0}$ & $\mathbf{C 1 8 : 1 0 H}$ \\
\hline HO Canola & 4.2 & 2.7 & 71.3 & 12.3 & 3.9 & 2.3 & 2.7 & 0.2 & \\
HO Safflower & 5.2 & 2.5 & 72.8 & 12.1 & 1.6 & 2.7 & 2.5 & 0.3 & \\
HO Sunflower & 3.7 & 3.8 & 87.4 & 2.5 & tr. & 0.4 & tr. & 1.1 & \\
HO Castor & 1.8 & 0.9 & 78.4 & 3.3 & 0.4 & & & & 14.0 \\
\hline
\end{tabular}

C16:0 = palmitic acid; C18:0 = stearic acid; C18:1 = oleic acid; C18:2 = linoleic acid; C18:3 = linolenic acid; C20:0 = araquidic acid;

$\mathrm{C} 22: 0$ = behenic acid; C20:1 = eicosenoic acid; $\mathrm{C} 18: 10 \mathrm{H}=$ ricinoleic acid.

hydroxylated ricinoleic acid that accounts for up to $85 \%$ of the fatty acids of this oil, conferring low pour points and very high viscosity to it. Castor oil has been extensively used in oleochemistry and lubricant formulations, although its use as a vegetable oil basestock is limited by its high levels of viscosity and the fact that it dehydrates and polymerizes at high temperatures (Asadauskas et al., 1997). Another oil basestock containing high levels of hydroxylated fatty acids is Lesquerella (Dierig and Ray, 2009). This oil also contains high levels of C20-C22 fatty acids, which add some extra viscosity to it, and is more unstable than castor oil due to its high levels of polyunsaturated fatty acids.

The accumulation of other monounsaturated fatty acids other than oleic would be also quite interesting to produce vegetable basestocks with better performances. Thus, palmitoleic acid $\left(16: 1^{\Delta 9}\right)$ displays similar stability to oleic acid but with a lower melting point (table 1). Palmitoleic acid is abundant in certain tropical nuts like macadamia or cat's claw (Gunstone et al., 2007). In the past years genes coding for desaturases responsible for the synthesis of this fatty acid have been isolated and are ready to use for the production of oil crops enriched in palmitoleic acid (Cahoon et al., 2004). In this regard, a sunflower line producing up to $15 \%$ palmitoleic acid has been reported (Salas et al. 2007) to be produced by techniques of breeding and mutagenesis. However, the use of these mutants for lubricant production is hampered by their still high levels of linoleic and palmitic acids.
In recent years, interest has been paid to oils crops different to those used for food production. This would have the advantage of not directly competing with food stocks, which would involve rising the world market price of food, and keeping oils fated to industry segregated from those fated to normal commercialization, which would avoid contamination of edible oils with non-edible lubricant formulations. Some examples of these oil crops are Camelina sativa (Zubr, 1997), which is also an oil crop that can be easily genetically engineered, or safflower (Cartamus tinctorium), an oil crop with similar benefits to sunflower but whose production as a food stock has been almost totally abandoned.

\section{PROPERTIES AND USES OF LUBRICANTS BASED ON VEGETABLE OILS}

Vegetable oil basestocks have been extensively tested in the laboratory to investigate their properties in comparison to mineral oils. Their advantages and disadvantages will be discussed in this chapter.

\subsection{Friction properties of vegetable oils}

Unlike hydrocarbons in mineral basestocks, the molecular structure of TAGs includes ester bonds that add polarity to the lubricant, which means a better absorption of these oils into metallic surfaces. Studies on the free energy of the abdsorption $\left(\Delta \mathrm{G}_{\mathrm{ads}}\right)$ of different vegetable oils resulted in higher values 
Table 5

Fatty acid composition of high saturated sunflower mutants

\begin{tabular}{lccccccc}
\hline & $\mathbf{C 1 6 : 0}$ & $\mathbf{C 1 6 : 1}$ & $\mathbf{C 1 8 : 0}$ & $\mathbf{C 1 8 : 1}$ & $\mathbf{C 1 8 : 2}$ & $\mathbf{C 2 0 : 0}$ & $\mathbf{C 2 2 : 0}$ \\
\hline HP Sunflower & 35.7 & 6.3 & 2.1 & 9.8 & 43.1 & 0.3 & 0.8 \\
HS Sunflower & 7.2 & & 23.8 & 16.1 & 49.5 & 1.4 & 1.5 \\
HOHP Sunflower & 30.2 & 6.4 & 2.0 & 56.8 & 1.9 & 0.3 & 1.4 \\
\hline
\end{tabular}

C16:0 = palmitic acid; C16:1 = palmitoleic acid; C18:0 = stearic acid; C18:1 = oleic acid; C18:2 = linoleic acid; C18:3 = linolenic acid; $\mathrm{C} 20: 0$ = araquidic acid; C22:0 = behenic acid.

of this parameter for vegetable basestocks when compared with mineral ones, pointing to vegetable oil based lubricants as being more efficient in boundary conditions than regular mineral-based or monoesterbased ones (Biresaw et al. 2002; 2003). These studies also indicated that there were no important differences between different vegetable oils. Hence, high oleic oils performed similarly to regular vegetable oils with high levels of polyunsaturated fatty acids. Common laboratory lubrication tests measure antiwear, friction, scuffing, load capacity and fatigue resistance. Vegetable oils usually yield excellent results in these kinds of trials and they often improve the parameters resulting from mineral basestocks (Asadauskas et al., 1996; Arnsek and Vizintin, 1999; Adhvaryu, 2006). However, all these results should be considered with care, due to the fact that some of them are related to polymerization artifacts. So, Murakami and Sakamoto (2003) reported that the best results in the four ball tests on several vegetables basestocks corresponded to oils rich in linolenic acid in the presence of oxygen. The applicability of these results in practice would be limited due to oil polymerization, which should be avoided in any lubricant. Another remarkable property of vegetable oils is their high viscosity indexes which allow them to keep their lubrication properties at higher temperatures (Fasina et al., 2006).

\subsection{Uses of vegetable biolubricants}

Vegetable oil based lubricants have been demonstrated to work as excellent hydraulic fluids. Thus, hydraulic transmission fluids based on soybean and rapeseed oils have been extensively tested in both laboratory and field trials with excellent results. Remelle and Widmann (1999) performed a long term experiment with vegetable oil-based hydraulic fluid in agricultural machinery over a period of 6 years. The vegetable-based oil did not cause more damage or leakage than regular mineral oils while remaining biodegradable for the whole period of the test. Moreover, vegetable oil based lubricants have been tested for gearboxes (Hohn et al., 1999) and as cutting oils (Belluco and De Chiffre, 2000) and in both cases it was demonstrated that they were equivalent and in some aspects even better than mineral oils.

\subsection{Oxidation and degradation}

Vegetable oils make excellent lubricants at moderate temperatures but they only contribute to a small extent (2 to $5 \%$ ) to the whole lubricant oil market. The cause of this is the lower stability of vegetable basestocks against mineral oils. Therefore, one of the steps within the production of mineral basestocks involves the removal of unsaturated olefins in order to produce more stable saturated fractions. In the case of vegetable oils the reduction in unsaturation that can be obtained is limited due to linear saturated carbon chains which are solid at room temperatures, and so this reduction involves only the most unstable polyunsaturated fatty acids in the case of high oleic oils. However, high oleic vegetable bases, being more stable than other vegetable oils are still far from mineral bases.

The oxidation of vegetable lubricant basestocks has been previously reviewed (Fox and Stachowiak, 2007). This is a process involving a chain reaction initiated by the formation of free radicals through the removal of a hydrogen atom from the methylene group next to a double bond. The rate of $\mathrm{C}-\mathrm{H}$ breakage is much higher in polyunsaturated fatty acids, due to the free radical being stabilized by adjacent double bonds. This fact explains why monounsaturated fatty acids are more stable than their polyunsaturated counterparts. The reaction of propagation involves the production of hydroperoxides by reactions of free radicals with oxygen. Numerous reactions are produced as a consequence of hydroperoxide breakdown, which produces more free radicals. Reactions of termination involve interaction between two free radicals to yield a stable species. This process is often accompanied by TAG hydrolysis, producing a series of new compounds in the lubricant: free fatty acids, hydroperoxides, volatile and non-volatile oxidation compounds, and TAG polymers that alter the properties of the lubricant, increasing the wear and viscosity of the lubricant.

Most vegetable oils have been tested for their oxidative stability using the oil stability index (OSI). A good correlation between the fatty acid composition and the oxidation stability was found. The OSI ranged from 5.2 and 9.8 for standard oils and from 12.9 to 18.5 in high oleic ones (Lilon et al. 2008). Oxidative stability at high temperatures has also been studied in a collection of sunflower mutants with modified fatty acid composition in their oils (Fernandez-Martinez et al. 1997; Marquez-Ruiz et al. 1999). It was found that by increasing the amount of saturated fatty acids, like palmitic and stearic, the stability increased at $180^{\circ} \mathrm{C}$, and that the 
combination of high oleic plus high saturated fatty acids has a much better oxidative stability, even higher than palm olein (Marmesat et al. 2005).

The oxidation of the vegetable can be retarded by the addition of antioxidants. Tocopherols are antioxidants that occur naturally in vegetable oils. They are a family of compounds that act as free radical scavengers (Frankel, 1996). Among the different tocopherols the one called $\gamma$-tocopherol is the one conferring the highest protection to the oil, so oils rich in this compound will be more resistant to oxidation (Huang et al., 1994). Thus, from this point of view, corn and canola display tocopherol compositions conferring more protection than sunflower, where $\alpha$-tocopherol is the most abundant species within this family of compounds. Furthermore, there are many antioxidant additives that have been tested in vegetable oil basestock lubricants. They are compounds that act as radical scavengers or chain-breaking agents and involve a large variety of compounds that have been extensively reviewed (Becker and Knorr, 1996; Hamblin, 1999). The most extensively tested antioxidants are of the chain breaking type such as buthyl hydroxyl anisole, buthyl hydroxyl toluene, mono-terc-butyl hydroquinone or propyl gallate. Recently multiple functionality antioxidants of the type of zinc ditiophosaphates or thiocarbamates have been successfully tested. Other compounds indirectly improving the oxidative stability of vegetable oil basestocks are metal chelating agents and UV radiation absorbers.

\subsection{Pour points and viscosity}

Low temperature performance is one of the main drawbacks of using vegetable oils as lubricants. Petroleum-based hydraulic fluids can be satisfactorily used at temperatures as low as $-25^{\circ} \mathrm{C}$, whereas vegetable oil based ones display cloudiness, very high viscosities or are solids at temperatures around $-15^{\circ} \mathrm{C}$ (Hagemann, 1988). The cloud points of vegetable oils can be corrected to a certain extent by the addition of pour point depressants, which are branched polymetacrilates that interact with TAG crystallization. However, the improvement reached with those additives is limited when the exposition to low temperatures is longer than that used in the laboratory test. Other additives like synthetic diesters and polyol esters or oleates have typically been employed as diluents in biodegradable lubricants, and their effect on biodegrable lubricants has been extensively tested (Asadauskas and Erhan, 1999), reporting reductions in the pour points of vegetable oil basestocks to as low as $-24^{\circ} \mathrm{C}$.

Vegetable oils are also limited in their viscosity. The viscosity index required for lubricants can vary from $30 \mathrm{~mm}^{2} / \mathrm{s}$ at $40^{\circ} \mathrm{C}$ in the automation industry to $240 \mathrm{~mm}^{2} / \mathrm{s}$ for four stroke engines and some gear assemblies (Mang and Dresel, 2001). This range of viscosity cannot be covered by regular vegetable oils and so viscosity improvers have to be added for these purposes. Among the additives successfully used to increase viscosity, ethylene vinyl acetate copolymers and styrene-butadienestyrene copolymer in concentration ranges from 0.5 to $5 \%$ have been successfully used (Quinchia et al, 2009).

\section{ENVIRONMENTAL CONSIDERATIONS}

One of the main problems of pollution, even in developed countries, is the disposal of used lubricants. Amounts of 5.2 million tons/year of lubricant are consumed approximately in Europe, of which only $2-4 \%$ are vegetable oil-based. From that amount, 1.2 Million tons/year end up polluting the soil, water, air or are burned illegally (Directorate-General for the Environment of the European Commission and European Environment Agency). Spain consumed around 500,000 tons per year and an estimated 200,000 tons are lost. It is important to note here that $40 \%$ of the pollution in the rivers and lakes is due to lubricants and that $1 \mathrm{~kg}$ of mineral oil can contaminate 1,000,000 liters of water (Waste Oils, Directorate-General for the Environment of the European Commission). The European Union is regulating this area, legislating on the European eco-label on environmentally friendly lubricants (Official Journal of the European Union, May 5, 2005). The trend in the near future will be to use biodegradable and nontoxic biolubricants to prevent accidental pollution and reduce dependence on mineral oil, especially the total loss of lubricants in machinery that has a high probability of polluting the environment or lubricants that are in contact with food. To resolve all these problems, environmentally friendly lubricants are under development using vegetable oils as basestock oils, formulated with non-toxic and biodegradable additives.

\section{CONCLUSIONS}

Vegetable oil basestocks can be used to produce acceptable lubricants if they have the proper fatty acid composition and additives. They still display some disadvantages when compared with regular mineral basestocks. However, due to the advances in modern biotechnology, new improved basestocks will be soon available, narrowing the gap between these two types of lubricant. Furthermore, the environmental benefits and relative low costs of vegetable basestocks are, at present, a solid argument to promote its use. Hence, as a start, the use of low toxicity biolubricants should be enforced in environmentally protected areas and in the food industry.

\section{ACKNOWLEDGEMENTS}

This work was supported by MICINN (PSE-4200002008-4) and FEDER. 


\section{REFERENCES}

Adhvaryu A, Biresaw G, Sahrma BK, Erhan SZ. 2006. Friction behavior of some seed oils: biobased lubricant applications. Ind. Eng. Chem. Res. 45, 3735-3740.

Arnsek A, Vizintin, J. 1999. Scuffing load capacity of rapeseed-based oils. Lubr. Eng. 55, 11-18.

Asadauskas S, Erhan SZ. 1999. Depression of Pour Points of Vegetable Oils by Blending with Diluents Used for Biodegradable Lubricants. J. Am. Oil Chem. Soc. 73, 313-316.

Asadauskas S, Pérez JM, Duda JL. 1996. Oxidative stability and antiwear properties of high oleic vegetable oils. Lubr. Eng. 52, 877-882.

Asadauskas S, Pérez JM, Duda JL. 1997. Lubrication properties of castor oil-potential basestock for biodegradable lubricants. Lubr. Eng. 53, 35-41.

Badami RC, Patil KB. 1980. Structure and occurrence of unusual fatty acids in minor seed oils. Progress Lipid Res. 19, 119-153.

Battersby NS. 2000. The biodegradability and microbial toxicity testing of lubricants: some recommendations. Chemosphere 41, 1011-1027.

Becker R, Knorr A. 1996. An evaluation of antioxidants for vegetable oils at elevated temperatures. Lubr. Sci. 8, 95-117.

Belluco W, De Chifre I. 2000. Testing of vegetable-based cutting fluids by hole making operations. Lubr. Eng. 57, $12-16$.

Biresaw G, Adhvaryu A, Erhan SZ. 2003. Friction properties of vegetable oils. J. Am. Oil Chem. Soc. 80, 697-704.

Biresaw G, Adhvaryu A, Erhan SZ, Carriere CJ. 2002. Friction and Adsorption Properties of Normal and High-Oleic Soybean Oils. J. Am. Oil Chem. Soc. 79, 53-58.

Cahoon EB, Coughlan SJ, Shanklin J. 2004. Characterization of a structurally and functionally diverged acyl-acyl carrier protein desaturase from milkweed seed. Plant Mol. Biol. 33, 1105-1110.

Campanella A, Rustoy E, Baldessari A, Baltanás MA. 2010. Lubricants from chemically modified vegetable oils. Bioresource Technology 101, 245-254.

Cermak SC, Isbell TA. 2001. Synthesis of estolides from oleic and saturated fatty acids. J. Am. Oil Chem. Soc. 78, 557-565.

Dierig D, Ray DT. 2009. New Crops Breeding: Lesquerella. In: Handbook of Plant Breeding vol. 4. Vollmann J and Rajcan I Eds. New York, USA, Springer, pp 507-516.

Erhan SZ, Asadauskas, S. 2000. Lubricant basestocks from vegetable oils. Ind. Crops Products 11, 277-282.

Fasina OO, Hallman $\mathrm{H}$, Craig-Schmidt $\mathrm{H}$, Clements $\mathrm{C}$. 2006. Predicting temperature-dependence viscosity of vegetable oils from fatty acid composition. J. Am. Oil Chem. Soc. 83, 899-903.

Fernández-Martínez JM, Mancha M, Osorio J, Garcés R. 1997. Sunflower mutant containing high levels of palmitic acid in high oleic background. Euphytica 97 , 113-116.

Fox NJ, Stachowiak GW. 2007. Vegetable oil-based lubricants - A review of oxidation. Trib. Int. 40, 10351046.

Frankel EN. 1996. Antioxidants in lipid foods and their impact on food quality. Food Chem. 57, 51-55.

García-Zapateiro LA, Delgado MA, Franco JM, Valencia C, Ruiz-Méndez MV, Garcés R, Gallegos C, 2010. Oleins as a source of estolides for biolubricant applications. Grasas y Aceites 61, 171-174,

Gunstone FD, Harwood JL, Dijkstra DJ. 2007. The lipid handbook. Boca Raton, Florida, USA: CRC Press.
Gunstone FD. 2004. Oxidation through reaction with oxygen. In Gunstone FD (Ed.) The Chemistry of Fats and Oils. Blackwell Publishing, Oxford, pp. 150-168.

Hagemann JW. 1988. Thermal Behavior and Polymorphism of Acylglycerols. In Garti N, sato K (Ed.) Crystallization and Polymorphism of Fats and Fatty Acids. Marcel Dekker, New York, pp 9-95.

Hamblin P. 1999. Oxidative stabilisation of synthetic fluids and vegetable oils. J. Synth. Lubr. 16, 157-181.

Hongtrakul V, Slabaugh MB, Knapp SJ. 1998. A seed specific $\Delta-12$ oleate desaturase gene is duplicated, rearranged, and weakly expressed in high oleic acid sunflower lines. Crop Sci. 38: 1245-1249.

Hohn BR, Michaelis K, Dobereiner R. 1999. Load carrying capacity properties of fast biodegradable gear lubricants. Lubr. Eng. 55, 15-36.

Huang SW, Frankel EN, Bruce German J. 1994. Antioxidant activity of alpha and gamma tocopherols in bulk oils and in oil-in-water emulsions. J. Agric. Food Chem. 1994 42, 2108-2114.

Isbell TA, Lowery BA, De Keyser SS, Winchell ML, Cermak, SC. 2006. Physical properties of triglyceride estolides from lesquerella and castor oils. Ind. Crops Products 23: 256-263.

Lilon I, Merrill O, Pike A, Ogden LV, Michael LD. 2008. Oxidative Stability of Conventional and High-Oleic Vegetable Oils with Added Antioxidants. J. Am. Oil Chem. Soc. 85, 771-776.

Mang T, Dresel W. 2001. Lubricants and lubrication. Wiley-VCH. Weinheim. Germany.

Marmesat S, Mancha M, Ruiz-Méndez MV, Dobarganes MC. 2005. Performance of sunflower oil with high levels of oleic and palmitic acids during industrial frying of almonds, peanuts, and sunflower seeds. J. Am. Oil Chem. Soc. 82, 505-510.

Marmesat S, Morales A, Velasco J, Ruiz-Méndez MV, Dobarganes MC. 2009. Relationship between changes in peroxide value and conjugated dienes during oxidation of sunflower oils with different degree of unsaturation. Grasas y Aceites 60, 155-160.

Márquez-Ruiz G, Garcés R, León-Camacho M, Mancha M. 1999. Thermoxidative stability of triacylglycerols from mutant sunflower seeds. J. Am. Oil Chem. Soc. 76, 1169-1174.

Murakami T, Sakamoto H. 2003. Lubricating Properties of Vegetable Oils and Paraffinic Oils with Unsaturated Fatty Acids under High-Contact-Pressure Conditions in Four-Ball Tests. J. Synth. Lubr. 20, 183-201.

Noureddini, H, Teoh BC, Clements LD. 1992. Viscosities of vegetable oils and fatty acids. J. Am. Oil. Chem. Soc. 12, 1189-1191.

Ohlrogge J, Browse J. 1995. Lipid biosynthesis. Plant Cell. 7, 957-970.

Quinchia LA, Delgado MA, Valencia C, Franco JM, Gallegos C. 2009. Viscosity modification of high-oleic sunflower oil with polymeric additives for the design of new biolubricant formulations. Environ. Sci. Technol. 43, 2060-2065.

Remmele E, Widmann B. 1999. Suitability and Environmental Compatibility of Rapeseed Oil Based Hydraulic Fluids for Agricultural Machinery. J. Synth. Lubr. 16, 129-145.

Rojas-Barros P, de Haro A, Munoz J, Fernandez-Martinez JM. 2004. Isolation of a natural mutant in castor with high oleic/low ricinoleic acid content in the oil. Crop Science 44, 76-80. 
Rudnik LR. 2005. Synthetics, Mineral Oils, and BioBased Lubricants: Chemistry and Technology. CRC Press, New York, USA.

Salas JJ, Moreno-Pérez AJ, Martínez-Force E, Garcés R. 2007. Characterization of the glycerolipid composition of a high-palmitoleic acid sunflower mutant. Eur. J. Lipid Sci. Technol. 109, 591-599.
Soldatov KI. 1976. Chemical mutagenesis in sunflower breeding In: Proc. 7th Int. Sunflower Association. Vlaardingen, The Netherlands. p. 352-357.

Zubr J. 1997. Oil-seed crop: Camelina sativa. Ind. Crops Products 6, 113-119.

Recibido: $28 / 4 / 10$ Aceptado: $31 / 5 / 10$ 